\author{
Daria JÓŹWIAK-NIEDŹWIEDZKA ${ }^{1}$ \\ Andrzej M. BRANDT ${ }^{2}$ \\ Karolina GIBAS ${ }^{3}$
}

\title{
OCENA MOŻLIWOŚCI WYSTĄPIENIA REAKCJI ALKALICZNEJ W BETONACH OSŁONOWYCH Z KRUSZYWAMI SPECJALNYMI
}

\begin{abstract}
Możliwość wystąpienia reakcji alkalicznej wodorotlenków sodu i potasu (Alkali Silica Reaction, ASR) w betonowych osłonach reaktorów wymaga szczególnej ostrożności przy doborze składników betonów do realizacji programu energii jądrowej w Polsce. Uszkodzenia osłon reaktorów w USA i w Belgii wskazują kierunki niezbędnych badań, [1-3]. W badaniach przedstawionych w artykule zastosowano kruszywa o dużej gęstości (osłabianie promieniowania gamma): magnetytowe, barytowe oraz hematytowe oraz kruszywo o wysokiej zawartości wody związanej (absorpcja promieniowania neutronowego) - kruszywo serpentynitowe. Przeprowadzono badania mikroskopowe kruszyw na cienkich szlifach w celu identyfikacji potencjalnie szkodliwych minerałów z uwagi na zagrożenie ASR, oraz przyspieszone i długotrwałe badania w celu określenia potencjalnej reaktywności alkalicznej tych kruszyw. Wyniki badań wykluczyły możliwość stosowania kruszywa hematytowego do betonów osłonowych. Wyniki badań odnośnie do wykorzystania dostępnych kruszyw specjalnych tworzą podstawy projektowania bezpiecznych osłon w warunkach krajowych.
\end{abstract}

Słowa kluczowe: reakcja krzemionki z wodorotlenkami sodu i potasu (ASR), ekspansja, beton osłonowy, kruszywo specjalne

\section{Wstęp}

Reakcja krzemionki z wodorotlenkami sodu i potasu (ASR, Alkali Silica Reaction) zachodzi w betonie między reaktywną postacią krzemionki z kruszywa a alkaliami zawartymi w cieczy porowej w zaprawie lub $\mathrm{w}$ betonie. Stanton [4] opisał to zjawisko w 1940 r. po wystąpieniu w Stanach Zjednoczonych poważnych uszkodzeń konstrukcji żelbetowych w postaci charakterystycznych rys, pęknięć i stopniowego zniszczenia. Liczne badania opublikowane w wielu kra-

\footnotetext{
${ }^{1}$ Autor do korespondencji/corresponding author: Daria Jóźwiak-Niedźwiedzka, IPPT PAN, Pawińskiego 5B, 02-106 Warszawa, djozwiak@ippt.pan.pl

${ }^{2}$ Andrzej M. Brandt, IPPT PAN, Pawińskiego 5B, 02-106 Warszawa, abrandt@ippt.pan.pl

${ }^{3}$ Karolina Gibas, IPPT PAN, Pawińskiego 5B, 02-106 Warszawa, kgibas@ippt.pan.pl
} 
jach doprowadziły do obecnej wiedzy o przyczynach ASR i sposobach ograniczenia występowania, np. Hobbs [5], Diamond [6], a w Polsce Owsiak [7]. Jednak wobec wyczerpywania się w wielu regionach złóż kruszyw do betonu całkowicie bezpiecznych, ASR pojawia się, także w Polsce.

Warunki niezbędne do powstawania ASR to [4-7]: obecność reaktywnej krzemionki w kruszywie, dostateczna zawartość alkaliów w cemencie, odpowiednio wysoka wilgotność i podwyższona temperatura konstrukcji betonowej, przy czym konieczna jest obecność wszystkich tych warunków. Takie sytuacje powstają między innymi w osłonach betonowych w elektrowniach atomowych, czego przykładem jest elektrownia w Seabrook NH, w USA [1], w której wystąpienie ASR spowodowało kilkuletnie wyłączenie reaktora i kosztowną naprawę czy elektrownia w Belgii (Tihange 2), gdzie całkowita degradacja betonu w konstrukcji budynku reaktora wywołana była jednoczesnym działaniem ASR i karbonatyzacji, [2]. Przykłady te pokazują, że zagadnienie ASR nie zostało uznane za poważne zagrożenie podczas doboru materiałów do konstrukcji elektrowni jądrowych.

Okazuje się przy tym, że promieniowanie jonizujące jest czynnikiem sprzyjającym powstawaniu ASR w osłonach betonowych w elektrowniach jądrowych. Ichikawa i Koizumi [8] stwierdzili, że w betonach pod wpływem promieniowania neutronowego rozwijała się reakcja alkaliczna i powstawały warstwy charakterystycznego żelu wokół ziaren otoczonych zaczynem cementowym. Wynikało to z przemiany kwarcu w kruszywie. Pod wpływem promieniowania krystaliczna forma kwarcu przechodziła w formę bezpostaciową, która to postać jest o wiele bardziej podatna na reakcję alkaliczną. Zwrócili na to uwagę już wcześniej Struble i Diamond [9] i wskazali, że łączne odkształcenia wywołane napromienieniem betonu były kilkakrotnie większe niż odkształcenia samych ziaren. Różnice wyjaśniono powstawaniem żelu wokół ziaren i pęcznieniem, co powodowało rysy i pęknięcia nawet $\mathrm{w}$ przypadkach kruszyw, które uznano wcześniej za pozbawione istotnych ilości reaktywnej krzemionki.

W zaleceniach opracowanych przez Nausa i in. [10] opisano przypadki rozwoju ASR w betonach osłonowych pod wpływem promieniowania także przy użyciu kruszyw uważanych za bezpieczne, co może prowadzić do poważnych uszkodzeń konstrukcji.

Wobec tych stwierdzeń, próbki wybranych kompozycji betonów osłonowych zbadane w ramach Projektu* ze względu na zagrożenie ASR są również poddawane działaniu strumienia neutronów w kanale topazowym reaktora MARIA. Celem jest zaobserwowanie oznak wpływu promieniowania neutronowego na odkształcenia i mikrostrukturę betonów, a w szczególności na rozwój ASR.

W referacie przedstawiono wyniki badań, pozwalające na ocenę zagrożenia zniszczeniem betonów osłonowych reaktora jądrowego wskutek reakcji alkalicznej kruszyw w zaprawach i betonach.

\footnotetext{
* Projekt "Trwałość i skuteczność betonowych osłon przed promieniowaniem jonizującym w obiektach energetyki jądrowej", PBSII/A2/15/2014"
} 


\section{Opis badań doświadczalnych}

\subsection{Materiały i próbki}

Ze względu na szczególne wymagania dotyczące kruszyw do betonu osłonowego dwie grupy kruszyw były badane: kruszywa o dużej gęstości z uwagi na promieniowanie gamma (barytowe, magnetytowe, hematytowe) i o wysokiej zawartości wody związanej (serpentynitowe) w celu osłabiania promieniowania neutronowego. Szczegółowy chemiczny skład kruszyw jest przedstawiony w publikacjach, [3, 11]. Kruszywa ciężkie charakteryzowały się następującymi gęstościami: barytowe $4,2 \mathrm{~g} / \mathrm{cm}^{3}$, magnetytowe $4,8 \mathrm{~g} / \mathrm{cm}^{3}$, oraz hematytowe $5,1 \mathrm{~g} / \mathrm{cm}^{3}$. Gęstość kruszywa serpentynitowego wynosiła $2,7 \mathrm{~g} / \mathrm{cm}^{3}$, ale co ważne ze względu na absorpcję strumienia neutronów, zawartość chemicznej związanej wody wynosiła $12 \%$ oznaczona wg DTA. Wszystkie kruszywa były zbadane za pomocą metody XRD w celu określenia składu mineralogicznego. Skład mineralny kruszywa barytowego to: baryt, kwarc i fluoryt, kruszywa magnetytowego - magnetyt, kordieryt i fluoroapatyt, kruszywa hematytowego - hematyt i kwarc oraz kruszywa serpentynitowego - chryzolit, antygoryt i lizardyt. Szczegółowe wyniki opisano w [12].

W badaniach zastosowano cement CEM I 42,5 R o zawartości alkaliów $\mathrm{Na}_{2} \mathrm{O}_{\text {eq }}$ równej 0,78\% wg XRF.

\subsection{Metody badań}

Analizę kruszyw przed badaniami laboratoryjnymi, oraz badania próbek zapraw po badaniach przyspieszonych przeprowadzono w mikroskopie polaryzacyjnym w świetle przechodzącym na cienkich szlifach. Próbki kruszyw oraz zapraw były poddane procesowi impregnacji żywicą fluorescencyjną, szlifowaniu i polerowaniu do otrzymania grubości szlifu równej $20 \pm 1 \mu \mathrm{m}$. Analizę cienkich szlifów przeprowadzono w świetle przechodzącym przy równoległych nikolach (PPL), skrzyżowanych nikolach (XPL) i skrzyżowanych nikolach z płytką gipsową, oraz w świetle ultrafioletowym (UV).

Z uwagi na złożoność zagadnienia ASR jak również na zmienność i różnorodność czynników mających wpływ na to zjawisko (złoża skał, minerały, warunki środowiskowe, i in.) nie ma przyjętej jednej ogólnej metody badawczej. Na potrzeby Projektu wybrano zestaw metod badawczych, który jest zawarty w amerykańskich normach ASTM. Metody C1260 i C1293 są najczęściej stosowane na świecie do oceny potencjalnej reaktywności alkalicznej kruszyw. Pośrednie metody badawcze dotyczą pomiaru ekspansji beleczek zapraw wg ASTM C1260 i belek z betonu wg ASTM C 1293, wykonanych z badanego kruszywa o potencjalnej reaktywności alkalicznej.

Badanie przyspieszone polegało na monitorowaniu zmian długości liniowej beleczek zapraw wykonanych z badanego kruszywa o żądanym uziarnieniu. Beleczki zapraw o wymiarach $25 \times 25 \times 285 \mathrm{~mm}$ przechowywano w $1 \mathrm{M}$ roztworze Na- 
$\mathrm{OH}$ w temperaturze $80^{\circ} \mathrm{C}$ przez 14 dni. Kryterium badania była wartość ekspansji równa $0,1 \%$ - kruszywo potencjalnie reaktywne i $0,2 \%$ - kruszywo reaktywne.

Roczne badanie w ASTM C1293 polegało na pomiarze ekspansji belek betonowych, wykonanych $\mathrm{z}$ badanego kruszywa oraz kruszywa nieaktywnego. $\mathrm{W}$ tej metodzie zakłada się możliwie ostre warunki oddziaływania alkaliów z cementu na kruszywo, poprzez ustaloną stałą zawartość alkaliów. Zawartość cementu w betonie wynosi $420 \mathrm{~kg} / \mathrm{m}^{3}$, przy ekwiwalencie $\mathrm{Na}_{2} \mathrm{O}_{\text {eq }}$ korygowanym do $1,25 \%$ masy cementu, co $\mathrm{w}$ wyniku daje $5,25 \mathrm{~kg}$ alkaliów na $1 \mathrm{~m}^{3}$ betonu. Pomiary ekspansji prowadzone są na belkach o wymiarach $75 \times 75 \times 285 \mathrm{~mm}$, przechowywanych $\mathrm{w}$ warunkach wysokiej wilgotności w temperaturze $38^{\circ} \mathrm{C}$. Miarą reaktywności kruszywa jest wartość ekspansji powyżej 0,04\% mierzona po 1 . roku dojrzewania próbek betonu.

W badaniach zastosowano cement CEM I 42,5R o zawartości alkaliów $\mathrm{Na}_{2} \mathrm{O}_{\text {eq }}=0,78 \%$ oznaczonych metodą XRF. W zaprawach stosunek kruszywa do cementu wynosił 2,15 a współczynnik wodno-cementowy w/c=0,47. W betonach jako niereaktywne kruszywo zastosowano wcześniej zbadane kruszywo granodiorytowe, współczynnik w/c=0,45.

\section{Wyniki badań i dyskusja}

Szczegółowy opis analizy składu mineralogicznego badanych kruszyw znajduje się w pracach $[6,10]$. Na cienkich szlifach w XPL z płytką gipsową przy pomocy automatycznej analizy obrazu określono zawartość kryształów $\mathrm{SiO}_{2}$, który ma bezpośredni wpływ na wystąpienie ASR. Zawartość wysoko reaktywnego kwarcu (kryształy $<10 \mu \mathrm{m}$ ) wynosiła $0,08 \%$ a reaktywnego kwarcu (kryształy $10-60 \mu \mathrm{m})-2,67 \%$. Wykazano zagrożenie ASR w kruszywie hematytowym z uwagi na zawartość kryształów kwarcu w zależności od ich wielkości, [13].

Wyniki badania ekspansji zapraw przedstawione są na Rys. 1 i potwierdziły powyższe przypuszczenia dotyczące zagrożenia wystąpieniem ASR. Wydłużenie liniowe wszystkich badanych beleczek zapraw zwiększało się wraz ze wzrostem czasu trwania testu, jednak tempo wzrostu ekspansji było zależne od zastosowanego kruszywa. Zaprawy z kruszywem hematytowym wykazały największy przyrost długości. Ekspansja w beleczkach była szybsza i większa w przypadku kruszywa hematytowego w porównaniu do innych kruszyw o dużej gęstości. Już po 7 dniach badania wydłużenie beleczek z kruszywem hematytowym przekroczyło wartość graniczną $0,2 \%$. Wszystkie beleczki z kruszywem hematytowym po 14 dniach badania wykazały przyrost długości około $0,30-0,35 \%$, co klasyfikuje to kruszywo jako bardzo reaktywne. Najniższa ekspansja była określona w zaprawach $\mathrm{z}$ kruszywem magnetytowym, ok. $0,02 \%$ po 14 dniach przechowywania w $1 \mathrm{M} \mathrm{NaOH}$ i $80^{\circ} \mathrm{C}$.

Analiza mikroskopowa próbek zapraw po badaniach laboratoryjnych na cienkich szlifach potwierdziła wyniki otrzymane wg metody przyspieszonej. Dowody wystąpienia reakcji alkalicznej zaobserwowano w próbkach zapraw $\mathrm{z}$ he- 


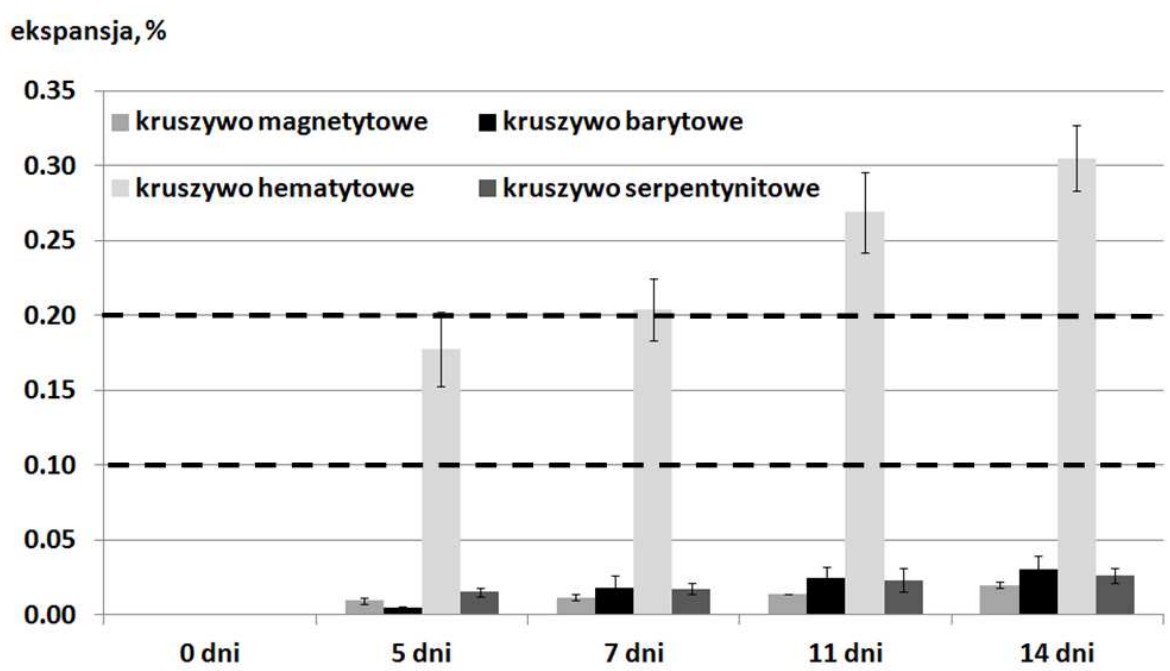

Rys. 1 . Wydłużenie zapraw przechowywanych w $1 \mathrm{M} \mathrm{NaOH}$ w temperaturze $80^{\circ} \mathrm{C}$ przez $14 \mathrm{dni}$

Fig. 1. Expansion of mortar beams stored in $1 \mathrm{M} \mathrm{NaOH}$ at $80^{\circ} \mathrm{C}$ during 14 days

matytem. Widoczne były spękania i mikropęknięcia w matrycy cementowej, charakterystyczny żel krzemionkowo-alkaliczny całkowicie wypełniał małe pory powietrzne i częściowo większe pory (> $500 \mu \mathrm{m}$ ), był widoczny także w matrycy, Rys. 2.

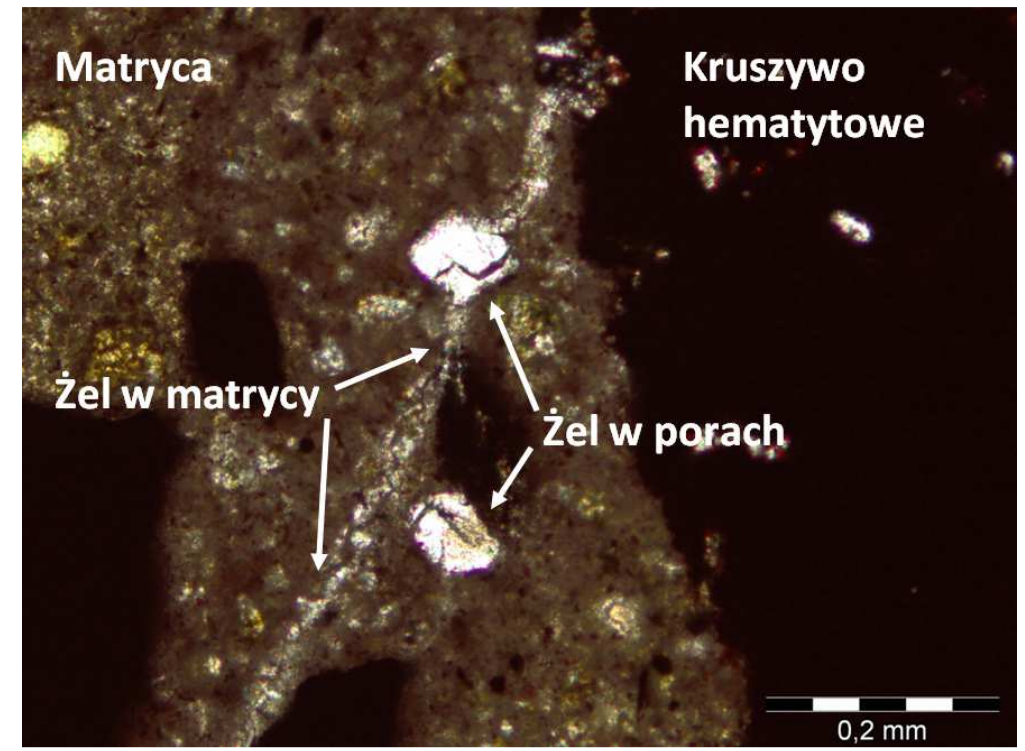

Rys. 2. Żel w matrycy i w porach w zaprawie z kruszywem hematytowym, PPL, skala $=200 \mu \mathrm{m}$

Fig. 2. Alkali-silica gel in the matrix and in the air-voids in mortars with hematite aggregate, PPL; scale bar $=200 \mu \mathrm{m}$ 
Do badań długotrwałych wg ASTM C1293 wybrano kruszywa, które pomyślnie przeszły badania przyspieszone. Wyniki rocznej ekspansji kruszywa magnetytowego, barytowego oraz serpentynitowego pokazano na Rys. 3. Wszystkie badane belki betonowe wykazały niewielki przyrost długości, poniżej granicy $0,04 \%$ po rocznym badaniu. Najlepsze wyniki osiągnął beton z kruszywem barytowym (ok. 0,025\%).

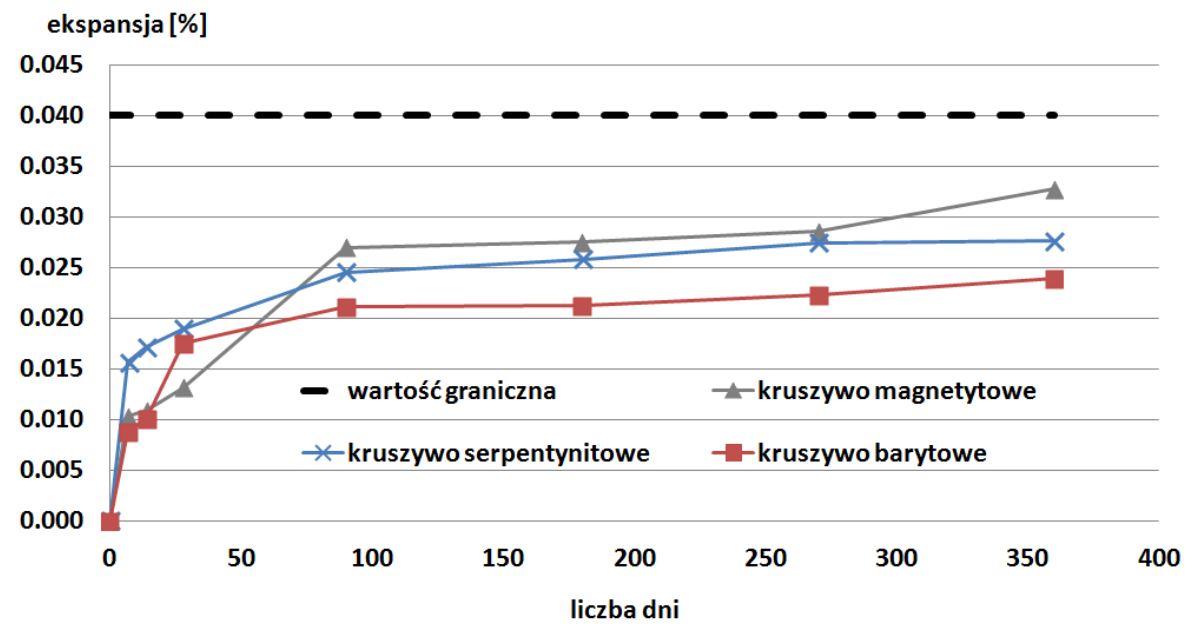

Rys. 3. Wydłużenie belek betonowych przechowywanych w $38^{\circ} \mathrm{C}$ w wilgotności $\geq 98 \%$ przez 365 dni

Fig. 3. Expansion of concrete beams stored at $38^{\circ} \mathrm{C}$ in R.H. $\geq 98 \%$ during 365 days

\section{Wnioski}

Na podstawie uzyskanych wyników badań mikroskopowych oraz przyspieszonych i długotrwałych badań laboratoryjnych można sformułować następujące wnioski:

- Wyniki analizy mikroskopowa na cienkich szlifach dotyczyły ilościowego określenia zawartości kryształów kwarcu w badanych kruszywach, odnośnie czego wykazano potencjalne zagrożenie z uwagi na ASR w kruszywie hematytowym.

- Przyspieszone badanie potencjalnej reaktywności kruszyw wykazało, że beleczki z kruszywem hematytowym charakteryzowały się dużą i szybką ekspansją, znacznie powyżej dopuszczalnego limitu.

- Analiza na cienkich szlifach z zapraw z kruszywem hematytowym po badaniu wg ASTM C1260 potwierdziła obecność żelu, zarówno w matrycy jak i w porach powietrznych. Kruszywo hematytowe zostało odrzucone w dalszych badaniach z uwagi na możliwość wystąpienia ASR.

- Kruszywa ciężkie: magnetytowe i barytowe, oraz kruszywo serpentynitowe pomyślnie przeszły długotrwałe badania laboratoryjne wg ASTM C1293. 
Ekspansja betonów z tymi kruszywami była znacznie poniżej wartości granicznej.

Dalsze badania polegające na silnym napromienieniu w reaktorze MARIA próbek betonu z wybranymi kruszywami specjalnymi są obecnie przeprowadzane.

\section{Podziękowania}

Artykut zostat przygotowany w ramach Projektu "Trwałość i skuteczność betonowych oston przed promieniowaniem jonizujacym w obiektach energetyki jądrowej", PBSII/A2/15/2014.

\section{Literatura}

[1] Seabrook Station, Unit no. 1, 2015, Feb 6, NRC Integrated Inspection Report, US NUREG Commission, 41 str.

[2] Sixth Meeting of the Contracting Parties to the Convention on Nuclear Safety, National Report, Kingdom of Belgium, Federal Agency for Nuclear Control, August 2013, 129 str.

[3] Jóźwiak-Niedźwiedzka D.; Gibas K.; Brandt A.M.; Glinicki M.A.; Dąbrowski M.; Denis P. (2015) Mineral composition of heavy aggregates for nuclear shielding concrete in relation to alkali-silica reaction, Procedia Engineering, 108, 162 - 169, DOI: 10.1016/j.proeng.2015.06.132.

[4] Stanton T.E. (1940) Expansion of concrete through reaction between cement and aggregate. Proc. Amer. Soc. Civ. Engrs, vol. 66, no. 10, 1781-1811.

[5] Hobbs D.W. (1988) Alkali-silica Reaction in concrete, Telford, London, 183 str.

[6] Diamond S. (1989) Mechanisms of alkali-silica reaction, Proc. $8^{\text {th }}$ Int. Conf. Alkaliaggregate Reaction, Kyoto, 83-94.

[7] Owsiak Z. (2002) Reakcje kruszyw krzemionkowych z alkaliami w betonie, Ceramika, Polski Biuletyn Ceramiczny, vol. 72, 107 str.

[8] Ichikawa T.; Koizumi H. (2002) Possibility of radiation-induced degradation of concrete by Alkali-Silica Reaction of aggregates, J. of Nuclear Science and Technology, 39 (8), 880-884, DOI: 10.3327 /jnst.39.880.

[9] Struble L.; Diamond S. (1981) Swelling properties of synthetic alkali silica gels, J. of the Amer. Cer. Soc., 64, 11, 652-655, DOI: 10.1111/j.1151-2916.1981.tb15864.x.

[10] William K.; Xi Y.; Naus D. (2013) A review of the effects of radiation on microstructure and properties of concretes used in Nuclear Power Plants, United States Nuclear Regulatory Commission (NUREG). 106 str.

[11] Jóźwiak-Niedźwiedzka D.; Glinicki M.A.; Gibas K. (2016) Potential For AlkaliSilica Reaction In Aggregates Designed For Shields Against Radiation, $5^{\text {th }}$ International Conference on Durability of Concrete Structures, June 30-July 1, 2016, Shenzhen University, Shenzhen, Guangdong, P.R. China, Paper Number \#1134, pp. 230235, DOI: $10.5703 / 1288284316137$.

[12] Jóźwiak-Niedźwiedzka D.; Brandt A.M.; Gibas K.; Denis P. (2014) The alkaliaggregate reaction hazard in the case of barite concretes, Cement Wapno Beton, $19,4,234-242$. 
[13] Jóźwiak-Niedźwiedzka, D.; Jaskulski, R.; Glinicki, M.A. (2016) Application of Image Analysis to Identify Quartz Grains in Heavy Aggregates Susceptible to ASR in Radiation Shielding Concrete, Materials 2016, 9 (4), 224, 1-14, doi:10.3390/ma9040224.

\section{ASSESSMENT OF THE POSSIBILITY OF ASR OCCURRENCE IN THE RADIATION SHIELDING CONCRETES WITH SPECIAL AGGREGATES}

\section{S u m m a r y}

The possibility of Alkali-Silica Reaction ASR in concrete shields in nuclear reactors in Poland requires particular attention in selection of concrete compositions. Damages in reactors in the USA and in Belgium may serve as indication for necessary investigations. In the research programme the high density aggregates were tested (for control of gamma radiation): magnetites, barites and hematites, as well as aggregates with high proportion of bound water - serpentinites for absorption of neutrons. Microscope analyses of aggregates on thin sections enabled to identify potentially dangerous minerals with respect to ASR. Accelerated and long term tests in order to determine potential reactivity of special aggregates were carried on also. The test results indicated clearly that hematites should be excluded for application in concrete shields. The safe aggregates available on the market were defined for application in the shields in Polish conditions.

Keywords: alkali-silica re action (ASR), expansion, shielding concrete, special aggregates

Przestano do redakcji: 07.06.2016 $r$.

Przyjęto do druku: 30.06.2016 r.

DOI: $10.7862 / \mathrm{rb} .2016 .15$ 